\title{
Achieving a win-win result in mega project delivery with suppliers through a different "partnering" approach
}

\author{
C. S. Chang ${ }^{1} \&$ H. N. S. Cheung ${ }^{2}$ \\ ${ }^{1}$ Kowloon-Canton Railway Corporation, Shek Mun RS Site Office, Shatin, \\ Hong Kong \\ ${ }^{2}$ Kowloon-Canton Railway Corporation, KCRC House, Fotan, \\ Hong Kong
}

\begin{abstract}
Project managers and project engineers are facing the biggest ever difficulty in specifying suitable software based electronic control and communication systems for major railway projects which normally takes up to five years to build from the day appropriate approval is given by the relevant authority. The changes in the technologies, from the hardware components such as CPU and memory chips to the operating systems like Windows all the way down to the communication protocols and mechanisms including both wired and wireless applications, are taking place in such a high speed that five years can easily span two generations of these technological products, if not three.

While most of the specifications these days tend to be functional and performance oriented with a hope that the responsibility of delivering the most up-to-date and proven technologies would be vested with the lucky (or "poor") selected supplier, the outcome usually back fires on the client who has to either suffer from using obsolete technologies lacking the required support from the original system manufacturers or be the first real user of a technology which normally comes with loads of "unwanted features" and "unpredictable" system performance. What is even worse is that it would end up with contractual disputes, which could possibly benefit neither party but the lawyers.

This paper attempts to describe an innovative "partnering" approach in working with the suppliers right from the Tendering Stage through to the Contract Delivery and Site Testing to ensure advanced state-of-the-art yet functional and "proven" control and communications systems be practically specified and hence delivered by the suppliers over a relatively long project duration. With this approach, which has been tried in one of the past projects that the author has participated in, it is believed that a win-win situation between the client and the supplier could be achieved meeting the fundamental project mission of on time and within budget delivery.
\end{abstract}

Keywords: project management, project lifecycle, contracting strategy, signalling, control and communication system. 


\section{Introduction}

With the breakthrough in micro-electronics leading to the invention of VLSI, users of any electronic based application systems are enjoying the benefits of being able to be provided with low cost product upgrade leading to higher performance and more diverse functionalities. This is being the case for the home PC users who are getting a lower cost yet much more powerful system every 3 to 5 years. However, this is not necessary true to those mission critical or safety critical systems including the railway control and communication applications where the cost of designing and hence testing of the applications takes about more than $75 \%$ of the total cost of the systems. Upgrading the basic hardware and software platforms implies that it would take them more than $50 \%$ of the total cost to retest. Stability of the basic technological platforms becomes a priority for this type of critical applications.

For the past twenty years in handling projects of this kind and in view of the rising trend of using commercial off-the-shelf (COTS) technological platforms, the authors have tried different approaches in selecting the suppliers as well as the technologies for mission critical applications in railway. It is concluded that an innovative partnering approach in working with the suppliers well before the Tendering Stage through to the contract delivery and site testing to ensure advanced state-of-the-art yet functionally proven control and communications systems could be practically implemented over a relatively long project duration. This approach has been tried out in one of the past projects that the authors have managed.

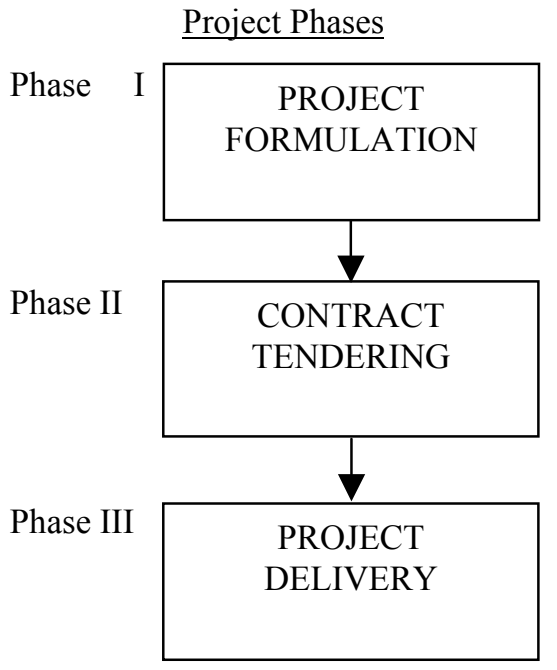

\section{Traditionally}

- Client to formulate the specifications for Tendering based on its operational requirements with no or minimal inputs from potential suppliers.

- Suppliers to bid based on published specifications with minimal communication with client to maintain "fairness" \& "Confidentiality".

- Selected supplier to design, develop, manufacture, test and commission and client to review and to accept or otherwise.

Figure 1: Typical project lifecycle. 


\section{Typical control and communication systems project lifecycle}

As a result of globalization, major railway projects to be executed in Hong Kong have to be complied with the World Trade Organisation (WTO) regulations. This implies an open tendering process has to be put in place to all the potential suppliers worldwide as far as practicable. Figure 1 depicts the key phases of the life cycle for a typical Control and Communication project.

\subsection{Project formulation}

Traditionally, a project is formulated by a team of "expert" engineers. The team will normally liaise with the end users (operators and maintainers) to define the high-level user requirements, both functional and performance. Based on the user requirements, a technical study will be carried out to formulate a project estimate for endorsement. As minimal interaction with the potential suppliers usually takes place throughout the whole process, the specified system is solely based on the knowledge and the experience of the project/consultant team. A typical workflow of the activities for this phase is given in Figure 2.

PROCESS

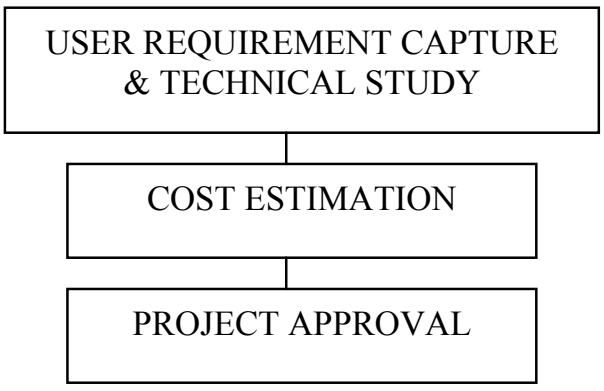

\section{OUTCOME}

User Requirement Definition Report and Technical Study Report (With Specifications)

Project Cost Estimate

Contract Tender Package

Figure 2: $\quad$ Project formulation phase.

\subsection{Contract tendering}

Under WTO, express of interest (EOI) will be advertised in both local and overseas newspapers and a few suppliers with proven past track records will be pre-qualified to go to the tendering stage. Throughout tendering as no direct communication between the tenderers' and the client's engineering teams is allowed to ensure "fairness", only paper communication through Q\&A will take place to clarify any queries. Such paper communication always ends up with misunderstanding between the final selected supplier (the contractor) and the client (the employer). 
In addition, under a competitive bid arrangement, some tenderers would usually try to cut some corners in order to reduce the bid total for winning the contract. Such action may not be visualized by the client until later on in the project delivery phase when the system is being designed or developed. Figure 3 shows the activities involved in the contract tendering phase.
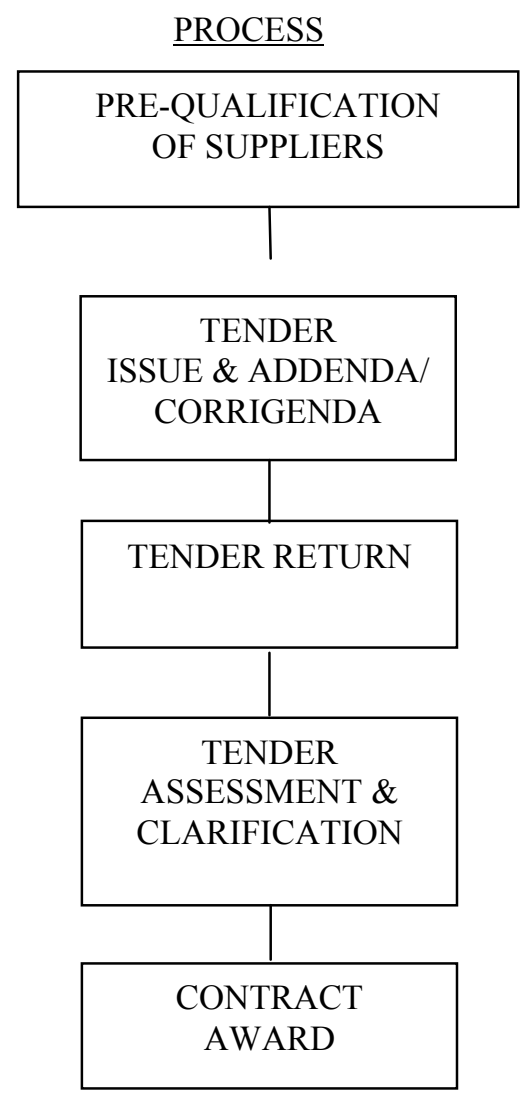

\section{OUTCOME}

Though open to all, only prequalified suppliers are selected for tendering in view of their capability and relevant experience

Tender sent to pre-qualified tenderers and amendments may be made to the Tender after it is issued

Complete Tender Packages returned from tenderers (both technical and commercial proposals are fixed)

Clarifications on the Tender Packages are sought

Contract is awarded to the selected supplier

Figure 3: $\quad$ Contract tendering phase.

\subsection{Project delivery}

Most of the control and communication system projects in railway tend to be on a design and build basis, i.e. only functional and performance specification is included in the tender and the final selected supplier is responsible for the design and development of the system. Most clients nowadays have a strong preference in using standard COTS products to develop their applications in order to save cost though the performance and reliability of these COTS products are always a concern. It is also rather unfortunate that lacking of universal standards to allow 
a simple "plug and play" type of connections among systems results in dedicating very much effort, in terms of time and human resources, in building an integrated control system. This could result in having contractual disputes between contractors and the client.

\section{An innovative partnering approach}

In order to allow the control and communication system to be specified in such a way that when it is delivered to revenue operations, the technologies so adopted will still be the latest yet proven, an innovative partnering requiring the suppliers and the client to work very closely together is proposed. Figure 4 shows the process flow for this approach.

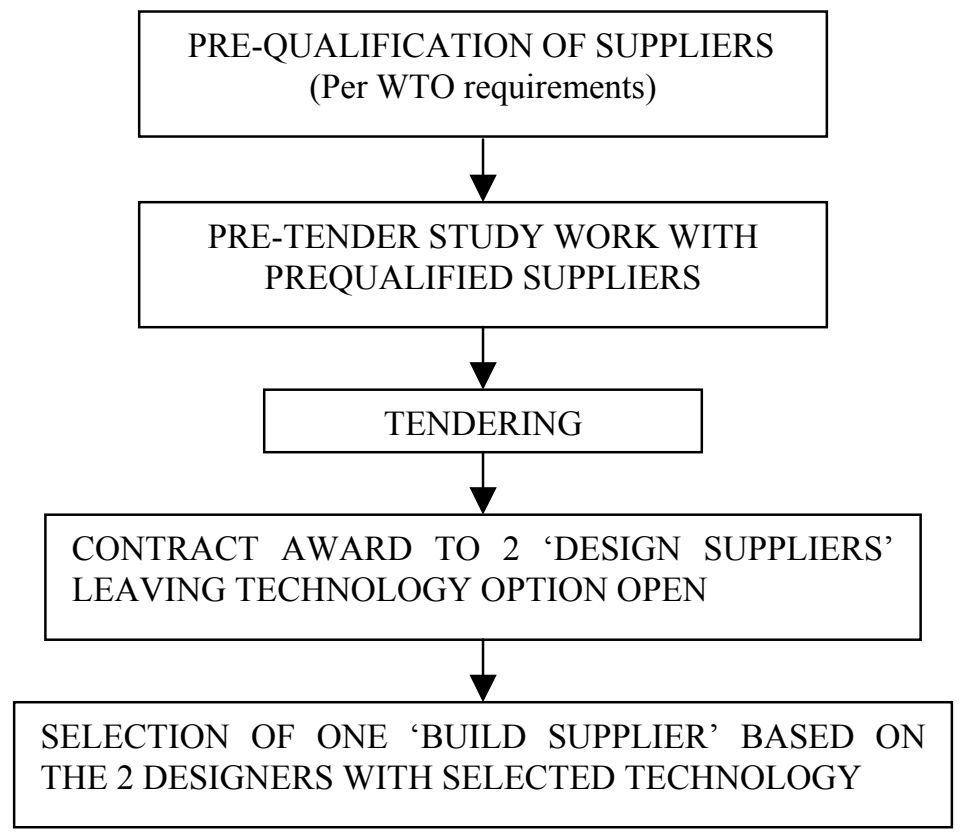

Figure 4: $\quad$ Process flow for innovative partnering approach.

\subsection{Pre-qualification of suppliers}

Invitation for EOI to all potential control and communication system suppliers will take place in the partnering arrangement as in the conventional approach. A group of suppliers will be selected and transition to the next phase of process.

\subsection{Pre tender study work with pre-qualified suppliers}

Instead of solely using an expert team to develop the user requirements in the form of user requirement definition report for the production of tender 
specification, the pre-qualified suppliers are requested to take part in this requirement capture process and to provide inputs to ensure what the users want is fully understood. This process requires a dedicated team comprising of the end users and project team to acquire an in-depth understanding of the suppliers' systems through technical visits and discussions. This will result in producing a set of solid functional and performance requirements, which forms the basis of the tender specifications. Critical internal review will then be conducted before tender issue.

As this process involves fairly extensive participation of the pre-qualified suppliers, the client should be prepared to set aside a fixed lump sum of money for each supplier so that they would dedicate the right level of resources to support the work.

\subsection{Tendering}

The conventional tendering process will be carried out with an objective to select the best TWO cost / performance suppliers to conduct the intensive detail design work. The purpose of selecting two design contractors for the same project is to ensure that the detail design of system which is based on the COTS platform of the corresponding supplier can fully meet the users' expectation. It is often the case that the deficiencies of the supplier's platform could only be identified during the various design stages. Including one more supplier in the design stage would increase the chance of designing a system that will fully meet the users' requirements.

\subsection{Contract award to two 'design suppliers' leaving technology option open}

Under this approach, it is worth mentioning that the technology to be adopted for the system development can be left open till the conclusion of the final design. This approach allows the most up-to-date yet proven technology to be chosen for the development of the system. Furthermore as only one of the two design contractors will be able to go to the final phase, they would be more flexible in ensuring their design and hence their selection of technologies would be most suitable to fulfil the users' needs. Though the cost of the design work is nearly a double, it only accounts for about 10 to $15 \%$ more on the total project cost. Such percentage could be easily expensed in the form of variations and / or claims in the later part of project lifecycle under the conventional project management approach due mainly to the lack of the understanding on the limitations of the Supplier's standard platform. While the design work for both the contractors is being carried out in parallel, the overall programme of work is not jeopardized.

\subsection{Selection of one 'build contractor' based on the two design contractors with selected technology}

Based on the final design generated by the two design contractors and their original tender proposals on the 'Build' of the system, a build contractor will be 
appointed under a set of clearly defined criteria. This build contractor will develop, implement, test and commission the system for revenue operation.

It is worth noting that a backup option is available in case the selected 'build contractor' cannot deliver due to whatever reasons, the other design contractor is a readily available alternative with detail design ready for proceeding with their Build work. This would mitigate the risk of a design and build contractor who decides to "walk away" half way down the project programme.

\section{Case study - KCRC West Rail Signalling Contract procurement}

\subsection{West Rail signalling system}

In 1996, when KCRC was to decide on a tendering strategy for the West Rail signalling system, we faced a very difficult situation: the West Rail user's requirements on performance, reliability, availability, maintainability and safety were extremely demanding. We faced a risk that we were not certain any of the suppliers in the market would be able to meet all these stringent criteria. On the other hand, we did not want to soften these requirements so that the project risks could be minimised.

The solution to this problem was one that was considered to be an innovative approach to an otherwise contradicting requirement: KCRC would develop its signalling system requirements jointly with the industry - the funnel process. The fundamental concept of the funnel process was that the employer would look at the best achievable performance of the available systems on the market, review and refine the user's requirements, before going for tender. As a result, the tendering period had to be lengthened substantially to allow for a decent study to be conducted.

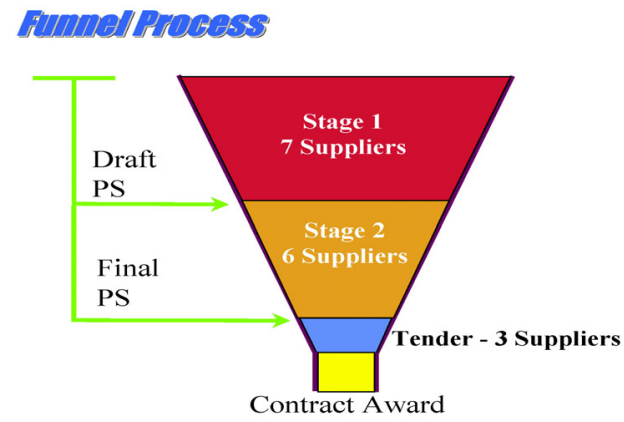

Figure 5: $\quad$ Funnel process for KCRC West Rail signalling contract.

This process also provided benefits to the suppliers intended to undertake the works as they would be able to influence the specification to eliminate the 
impossibilities and to reduce project risk by eliminating misunderstanding and differences in interpretation of the requirements.

A critical element for this funnel process to work is that the specification must be performance based. This would provide more flexibility for the supplier to propose their most prudent solutions to meet the specification. However, the user must have thorough understanding of the supplier's system or the result would be an unpleasant surprise. This is why part of the funnel process has to be a visit to the suppliers' installed facilities. Figure 5 illustrates the funnel process adopted for the KCRC West Rail signalling contract.

\subsection{The funnel process}

Prior to Stage 1, KCRC followed the standard procedure of tender prequalification, inviting the industry to submit their intention to bid for the contract. Seven suppliers were selected to enter into the funnel process. Since this would be a one-year long programme, KCRC compensated the seven suppliers with a nominal fee for their effort to take part. The funnel process commenced in July 1997.

During Stage 1 of this exercise, the suppliers were given a copy of the Operations and Maintenance (O\&M) Plan for West Rail. In this O\&M Plan, the basic requirements including mode of operations (such as traffic pattern, hours of operations and minimum headway), passenger flow forecast, train data (train length, traction and braking performance, etc.), and reliability, availability, maintainability and safety (RAMS) targets were given.

The suppliers were requested to submit a proposal outlining their system design, characteristics, configuration, and equipment locations and quantities. This proposal provided KCRC an insight into the system performance, strength and weakness. This formed the basic framework for KCRC to determine the details for the performance based specification, and potential areas of concern.

The suppliers were also asked to provide one or two reference sites where the proposed system had been in operations. These visits allowed KCRC an opportunity to discuss with the end users of the concerned systems the way these systems operate. The result would be a more comprehensive, relevant and workable specification. At the end of Stage 1 of the funnel process, KCRC evaluated the system proposals from the suppliers, and invited six of the seven to proceed to Stage 2.

In Stage 2, the suppliers were asked to review and comment on the draft particular specification (PS) of the Signalling Contract. This draft PS was completed based on the information from the O\&M Plan, suppliers' proposals from Stage 1, international standards, current industry best practices, and results from the visits to the operators. The comments from these Stage 2 suppliers would be fed into the revision of the PS, which would form part of the final tender package.

In addition, the suppliers was requested to perform a headway simulation based on the current alignment and train performance data and a perturbation analysis demonstrating the capability of their system to recover from a 5-minute delay occurred at the middle of the line. These simulation results were used to 
refine the track geometry, alignment, and possibly the locations of points and crossings. This gave KCRC an opportunity to fine-tune their design prior to construction works. In addition, KCRC would be able to determine if their intended operational headway could be achieved by the industry.

At the completion of Stage 2, 3 suppliers were invited to tender for the contract. At the same time, the specification would be finalised, ready for tendering. The funnel process was successfully completed in July 1998 and the contract was finally awarded in February 1999.

\subsection{The funnel process}

Now that it is almost 9 years since the commencement of the funnel process, with West Rail over two years in operations, we can now summarise the results of the process. The contractor was well aware of the requirements from the beginning of the contract, and that there was no uncertainty and misunderstanding in the interpretation of the contract. They were able to complete all stages of the works on time, with only minor amendments to the design. The end users understood the system performance, leading to relatively fewer change requests. The variations on the contract were less than $10 \%$ of the contract sum. Since the contractor and KCRC had worked together for over one year before the commencement of the contract, the working relationship had been established to facilitate the execution of the project under informal partnering approach.

Note that the signalling system operations for West Rail is different from that of the other lines in KCRC; however the operation staff was aware of this difference from the beginning of the funnel process and there was no "cultural shock" when they took over the system in 2003. In fact, they have been working together with the contractor that the operation staff were fully competent on Day One operations.

\section{Conclusion}

The past two decades have witnessed a rapid change in technologies in the IC development resulting in a need to drastically and critically review the way mission critical computer based control and communication system projects are to be managed. All these systems carry the unique characteristics of relatively long design and development duration before they are put into actual operation and a relatively long operational life span of no less than 10 years. It is almost impossible for any supplier to propose a technology at the beginning of tendering that is still considered to be "live" by the time it is commissioned for use.

In addition, the understanding of the COTS products in association with the unique and demanding user's requirements for railway systems is of extreme importance to ensure the success of the projects.

An innovative partnering approach is proposed by the authors in this paper. The concept was tried out in the KCRC West Rail signalling project, which is now proved to be workable and constructive by reducing the unnecessary 
misunderstanding, confusion and frustration leading to possible programme delay and cost overrun. A win-win result was managed to be achieved in this mega project delivery for on time opening of West Rail in 2003.

\section{Acknowledgements}

The authors wish to express their sincerest thanks to Mr. K K Lee, Senior Director - Capital Projects, Mr. Terence Law, Project Manager - Rail Control Systems and Mr. K W Pang, Signalling and Communication Manager for their review and valuable comments given to this paper. The authors also wish to thank KCRC for their permission in publishing this paper in the conference. 